\title{
A simple method to optimise Kirschner wire fixation of hand fractures
}

\author{
Waseem Bhat • David Mather
}

Received: 2 May 2010 /Accepted: 24 May 2010 /Published online: 19 June 2010

(C) Springer-Verlag 2010

Sir,

Kirschner (K-) wiring is a simple but effective method for holding hand fractures in a reduced position, allowing mobilisation. While placing $\mathrm{K}$-wires, it is of paramount importance to get the path of the wire correct to provide optimum fracture reduction whilst subjecting the tissues to minimal heating [1].

We present a simple method to aid the accurate placement of wires with minimal attempts.

A K-wire is used to map out the desired orientation to the wire (Fig. 1) with the aid of X-ray. A marker pen is then used to draw this line on the skin (Fig. 1). The wire is then placed percutaneously using the pen mark as an aid to the three-dimensional spatial awareness needed for competent positioning.

The combination of the two-dimensional image and the addition of tactile "feel" give the surgeon a better idea of wire direction, hopefully eliminating repeated passes of the wire into the bone. We have found this method to be a useful way to give confidence to the junior surgeon under supervision and may be used to construct a plan for more difficult fractures.

W. Bhat $\cdot$ D. Mather

Castle Hill Hospital,

Hull, Cottingham, UK

W. Bhat $(\bowtie)$

8 Nook Green,

Wakefield WF3 1ER, UK

e-mail: wbhat@hotmail.com

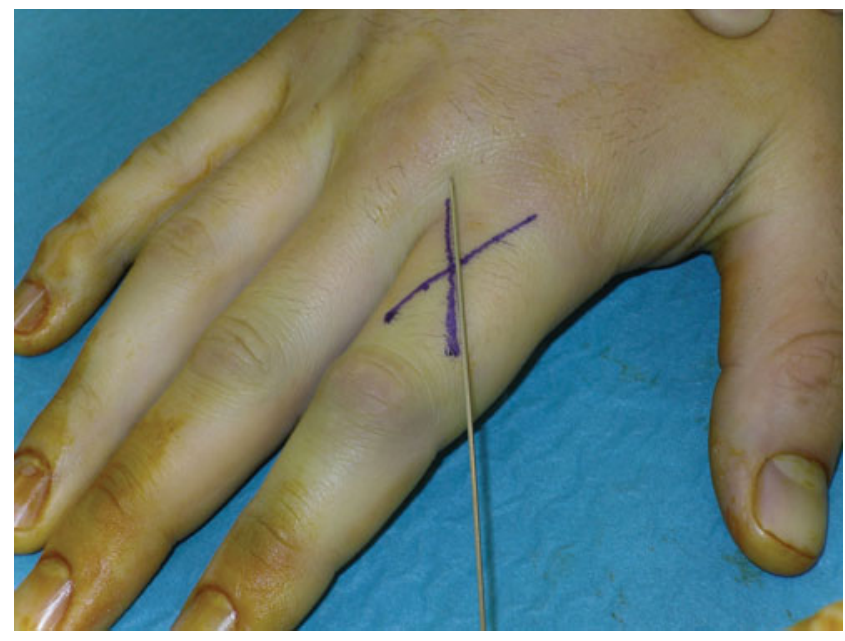

Fig. 1 K-wire placed over fractured phalanx to mark out desired direction of placement. Direction of K-wire marked on to skin with pen

If after visualisation under the image intensifier the position is suboptimal, the external lines act as a reference as to where the wire should go.

Conflict of interest We declare no conflict of interest (personal or financial) in the publication of this paper.

\section{References}

1. Matthews LS, Green CA, Goldstein SA (1984) The thermal effects of skeletal fixation-pin insertion in bone. J Bone Joint Surg Am 66 (7):1077-1083 